\title{
Analysing the Importance-Competence Gap of Distance Educators With the Increased Utilisation of Online Learning Strategies in a Developing World Context
}

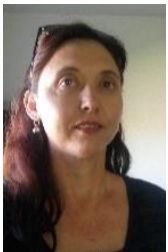 \\ Adéle Bezuidenhout \\ University of South Africa, Department of Human Resource Management
}

\begin{abstract}
The competence of distance educators has a significant impact on learners' success. The paradigm shift for universities to become distance and electronic learning environments justifies the urgency to address competency gaps in distance educators' competencies efficiently. From a strategic human resource development perspective, the systems theory is used to explain the idea of maximising outputs with the minimum inputs (Biddle, 1986). In this study, distance educators at Unisa reflected on their experienced competency gaps. Where previous studies mainly focus on the size of the gaps, the aim of this article is to highlight the competency gaps likely to have the biggest impact. For this study, we used stratified non-probability sampling, and selected 407 academics who were, at the time of the study, permanently employed at a mega ODL university in South Africa. These academics represented a wide range of colleges, campuses, ages, and genders. The results of this study have implications for capacity building of academic staff in developing world contexts and other contexts where resources are scarce.
\end{abstract}

Keyword: academics, distance learning, faculty, importance-competence gap, online, staff development, training 


\section{Introduction}

The significant institutional shift from being an open distance learning (ODL) university (using a printbased mode) to becoming an open distance e-learning (ODeL) university, via an online mode, has a major impact on the work roles of distance educators (DEs) (Arinto, 2013). Technology-enhanced learning (TEL) in the Higher Education space, includes synchronous and asynchronous communication channels such as video conferencing, online messaging, e-mail, and various social media platforms (Gregory \& Lodge, 2015; Naidu, 2010). Panda and Mishra (2007) ascribe increased interaction, up-todate course material, and opportunities for collaborative learning to the use of TEL in Higher Education. They also argue that these technological innovations are responsible for the exponential growth of electronic distance learning models (Panda \& Mishra, 2017).

\section{Literature Review}

In turn, the competence of academic staff in using TEL may have a significant impact on the successful learning experience of distance learners. Preparing DEs to accept appropriate roles in an increasingly digitised environment, thus implies preparing them for a variety of evolving roles and related competencies (Bawane \& Spector, 2009). From this, it can be deduced that DEs constantly need to unlearn obsolete habits and behaviours, and learn new appropriate skills, knowledge, and behaviours. Training can be used strategically to attain the goals of the organisation and its employees. Training as strategy should be linked to the business's needs, performance effectiveness, and measurement of results (Rothmann \& Cooper, 2015). One of the main reasons for training is to improve the organisation's output and reduce costs (Rothmann \& Cooper, 2015). Universities need professional expertise and knowledge to function effectively as large, complex, and unique organisations in modern society (Altbach, 2014). According to Altbach (2014), universities are unique because they consist of communities of scholars, are major cultural resources, and are the "quintessential public good institutions" (p. 1307). The fluidity of the environment, dictated by the transformation and innovation in TEL and student agency for affordable Higher Education, further alter the field of play for all Higher Education stakeholders (Altbach, 2014). Seal and Cross (2016) refer to the "worrisome" (p. 1514) absence of research in developing world universities such as those in South Africa. Similarly, Kaunda (2012) calls for increased research in universities in the developing world context. My research aims to address these calls.

South Africa, as part of the Global South and developing world, is required to provide education to the masses in the interest of social justice, while maintaining developed world standards (Leibowitz, Bozalek, Van Schalkwyk, \& Winberg, 2015). DEs have to be empowered with the competencies they need to encourage learning in their large groups of students (Leibowitz, Bozalek, Van Schalkwyk, \& Winberg, 2015). Lovelock, Patterson and Walker (1998) proposed importance-performance analysis as a very useful management tool to direct scarce resources to areas where it is likely to have the biggest impact. Seale and Cross (2016) note the internal competition for dwindling resources in South African universities and the pressure experienced by deans, to "do more with less," (p. 1522) is adding to the complexities faced by policy makers in developing world universities. This study is different from previous studies on DE competencies, in that previous studies mainly focus on identifying competency gaps (Arinto, 2013). The end result of such studies is a wide-ranging list of new competencies to be addressed, where time and money are limited. The question of where to focus immediate interventions thus remains; training interventions may incorrectly be aimed at eliminating the biggest skill gaps, regardless of whether these skills are important or not. 
In addition, regarding time as a limited resource, Gregory and Lodge (2015) refer to workload as a "silent barrier" (p. 1) to the implementation of TEL, alluding to the fact that the DEs time is restricted and that therefore, they must carefully prioritise the skills training interventions they attend. This implies that universities need to find a way of investing the smallest amount of resources to achieve the most efficient and effective outcomes. To address this need, this study follows an approach originally used in business theory developed from the original importance-performance analysis (Martilla \& James, 1977). This approach dictates that the specific characteristics of DEs are categorised as strengths and weaknesses in terms of two important criteria: importance and competence (Martilla \& James, 1997).

Although competency models are a key tool in human resource development (HRD) and management systems and practice (Markus, Cooper-Thomas, \& Allpress, 2005), existing literature acknowledges the confusion between the terms competence and competency (Axley, 2008). Some authors use the terms interchangeably (Axley, 2008), while others distinguish between the terms (De Coi et al., 2007). In their competence gap analysis model, De Coi et al. (2007) view competency as a general description of the requirements of human beings in or outside organisations. However, competencies are used to refer to the knowledge, skills, abilities, and attributes necessary to perform a job well (De Coi et al., 2007). Therefore, I believe that identifying competencies and using them as inputs to recruit, select, train, develop, and reward employees will improve organisational performance (outputs). This may also be likely to translate into an increased competitive advantage for the organisation, as the competencies needed to implement the organisations strategy can be taught.

According to Markus, Cooper-Thomas, and Allpress (2005), three main streams of interest in the concept of competency include:

1. Educational: development of skills, role outcomes, skills, knowledge, behavioural standards, narrow definition of competence as an action, behaviour/outcome/minimum standard, and award of credentials;

2. Psychological: McClelland and Boyatzis (1980) defined competencies as "a generic body of knowledge, motives, traits, self-images and social roles and skills that are causally related to superior or effective performance in the job" (p. 369); and

3. Business: The influential work of Hamel and Prahad (1989) added a "competitive advantage" lens popular with business strategists and introduced the idea of "core competencies" and "capabilities." Sparrow (1995) added the importance of defining higher level, future-oriented organisational competencies (Markus, Cooper-Thomas, \& Allpress, 2007, p. 117-118).

For the purpose of this article, distance faculty's competencies will be used to broadly refer to the skills, knowledge, motives, traits, and capabilities required to fulfil work roles successfully. The main research question is concerned with how the competency gap of academics teaching at a distance can be bridged. In summary, this article aims to use an importance-performance analysis to make recommendations on where training interventions may have the biggest impact on bridging distance learning academics' competency gap and in doing so, increase the effectiveness and efficiency of universities.

The ODeL context can be interpreted through the lens of the transactional distance theory (Moore, 2007), according to which the physical separation between academics and learners result in the 
experience of psychological distance between them. Referring to the cognitive space between the actors in an educational setting, the transactional distance theory has gained prominence as a seminal ODL theory, due to its relevance in this segregated context (Moore, 2007). In an ODL environment, the main actors, namely the academics and their learners, experience a sense of separation that is more than just a physical distance (Moore, 2007). According to Moore (2007), transactional distance is "a psychological and communication space to be crossed, a space of potential misunderstanding between the inputs of the instructor and those of the learner" (p. 91). The transactional distance between the DE and the learner needs to be bridged, as the success of distance learners depends greatly on the ability of the DE to create a sense of community and an engagement with the new subject matter (Moore, 2007). Moore (2007) specifically notes the importance of discourse or interaction between distance learning academics and their learners, the importance of a structure that supports meaningful learning, and the degree of autonomy or self-directedness that learners possess.

The social context of this study is Unisa, a mega ODL university in the developing world context of South Africa. As resources are limited in this context, there is a lot of pressure to be accountable, uphold good corporate governance, and spend taxpayers' money in the most efficient way possible. Furthermore, this institution is moving towards an online ODeL mode. The redesign of all modules for online delivery within a four-year period (2013-2016) put lot of additional pressure on all the university systems, but especially on academics (Poalses, Joubert, Bezuidenhout, \& Nienaber, 2014). The context brings with it additional challenges and societal dilemmas such as limited broadband capacity, lack of access to the Internet by learners, student agency against an ODeL mode, and labour unrest by sections of staff feeling threatened by a reduction in the amount of printing production needed by the institution. The increasing digitisation requires new competencies from all involved stakeholders, not least of which DEs. The need for intensive reskilling and the adoption of new attitudes and values require a significant investment in time, human resources, and financial resources in universities where resources are already stretched to the limit. For this reason, it is important for institutions to identify the areas of concern where they should focus their HRD efforts as a matter of priority to make the biggest positive impact.

HRD efforts improve the competency of academics and prepare them for future work roles (Okendu, 2012). Okendu (2012) also stresses the importance of continuous HRD in highly digitised academic contexts, where knowledge becomes obsolete quickly. With specific reference to the demands placed on distance learning academics to remain current with technological changes, he emphasises the importance of HRD programmes as a tool to update the competencies of distance learning academics (Okendu, 2012). Importantly, he links the competency of academic staff members with the "maximisation of learner achievement" (Okendu, 2012, p. 31).

To fully appreciate the implications, it is necessary to consider the relationship between roles, competencies, and training needs. The lens through which this paper reports research findings is HRD theory grounded in the systems theory (Biddle, 1986). This HRD theory states that employees are expected to fulfil certain predetermined, distinguishable work roles (Biddle, 1986) for which they need to have certain competencies, comprised of skills, knowledge, and attitudes. I believe DEs need to fulfil these roles competently to facilitate successful learning (maximise outputs). Thus, clarity of expected job roles and the consequent development of appropriate competencies are essential for the optimal performance of DEs. Previous research has indicated that appropriate learning and development 
programmes, underpinned by relevant competency development, are essential to equip DEs with the required skills, knowledge, and attitudes (De Coi et al., 2007; Lorenzetti, 2009; Varvel, 2007).

According to Berge (2008), traditionally, academics gained their knowledge, skills, and competence in their respective disciplines and not in education per se, and thus tend to be subject experts, rather than pedagogic experts. Adding to this, the dramatic changes in the work context of DEs over the past fifteen years has necessitated the mastery of new competencies (Berge, 2008). New expectations from learners, institutions, and society as a whole imply new tasks, roles, and responsibilities tied to the DEs' work role (Berge, 2008). As society is largely shaped by access to a wide range of information sources, including television, social media, and the Internet, learners have easy and convenient access to information, and the traditional view of the academic as the source of information has thus been altered (Berge, 2008). Learners may systematically need professors to facilitate their curation, understanding, and application of the big amount of knowledge that is freely available (Berge, 2008). Their need may be for the academic to act as a coach and mentor, instead of the sender of information (Berge, 2008).

In order to master these skills, the importance of effective staff development increases, however, Dimri and Misra (2006) acknowledge a paucity in the existing literature on staff development for distance education professionals. Norton (2008) defines staff development as the process of providing opportunities for improving knowledge, skills, and performance in line with the organisation's goals and the individual's needs. HRD and talent management interventions attempt to integrate the motivation and deployment of staff within the organisational system, to improve productivity (Norton, 2008). Current trends include staff development as a proactive, continuous, systematic process employing various activities (Norton, 2008). These activities include job rotation, coaching, mentoring, career development, performance appraisal, the building of personal strengths, and talent management initiatives (Norton, 2008). Baran, Correia and Thompson (2011) identified three aspects of current online faculty development programmes that are lacking: (a) the empowerment of academics, (b) promoting critical reflection on teaching practices, and (c) the integration of technology and pedagogical inquiry.

With the popularisation of ODL and online learning modes of delivery during the last fifteen years, change dimensions have been identified (Common Wealth of Learning and Asian Developmental Bank, 1999). Some of these change dimensions include the social context and clientele, generation, financial considerations, institutional pressures, societal changes, national programmes, and changing technologies (Common Wealth of Learning and Asian Development Bank, 1999). In my opinion, these dimensions are still relevant to the transition to an e-learning mode of delivery in most organisations.

In her research regarding the training needs of ODL academics, Bezuidenhout (2013) discovered that academics perceive regularly identifying training gaps in the fast-changing Higher Education environment as very important. The majority of academic staff members at Unisa indicated that the gaps in their competency levels were not continuously assessed (Bezuidenhout, 2013). From this flows a natural assumption that, if training gaps are not continuously and accurately identified, a situation may arise in which the university is training for the sake of training. Focussing on obsolete competencies without achieving any real change in the quality of work delivered by the parties involved may lead to frustration on the part of the institution, the academics, and the learners.

The increasing complexity of the ODL academics' job requirements thus demands strategic HRD interventions on the part of the ODL university. Although universities' resources are limited, a lack of 
targeted HRD interventions may lead to a less than desirable learning experience and a perception of poor service delivery by the student population. In terms of the systems theory (Biddle, 1986), this implies that outputs are not maximised with the available inputs. The question that arises is thus how and where the available resources should be applied (transformed) to make the biggest positive difference to the skills and competencies of academic staff. This article reports on the results obtained when the importance-performance theory (Lovelock, Patterson, \& Walker, 1998) is used as the theoretical framework to guide policy makers in deciding where to concentrate their strategic HRD efforts, to maximise service delivery and ultimately the learning that takes place in students.

From the viewpoint of the distance learners, Berge (2008) observes that major changes in the expectations of students lead to major changes in the way ODL academics are expected to perform their jobs, adding to the new competencies expected from faculty. Limited research has been conducted from an educational point of view on the new competencies expected from ODL academics, resulting in extensive lists of competencies and required training for ODL faculty members (Arinto, 2013; Baran, Correia, \& Thompson, 2011; Bawane, \& Spector, 2009) while overlooking the human incumbent of the academic work role. The effect of these increasing expectations unfortunately leads to an increase in cynicism, stress, and burnout in academics (Bezuidenhout \& Cilliers, 2010). Policy makers thus have to exercise discretion in adding to the job demands and workload of distance learning academics (Bezuidenhout, 2015).

In addition, universities often do not have the required resources in terms of time, money, and manpower to address all developmental needs with equal intensity and urgency. For this reason, this study focussed on identifying the importance-competency gaps that exist, with the purpose of identifying the most urgent gaps and providing institutions with some empirical evidence of where they should invest input to maximise output. The unique contribution of this research project is to identify the priority competency gaps viewed by ODeL faculty at Unisa as of paramount importance and make recommendations on how policy makers can maximise the outputs of the institution.

\section{Method}

This article is guided by a post-positivistic paradigm according to a quantitative, cross-sectional survey design. At the time of the research, the total number of full-time academics employed at Unisa, representing the entire hierarchy, was 1 614. According to Saunders, Lewis and Thornhill (2009), based on the size of the total population, a sample of $25 \%$ of the total population would be appropriate. For this reason, we selected 404 academic staff members to take part in our study. To facilitate generalisability of the results, a stratified random sample based on the academics' age, gender, rank, and faculty were drawn. A total of 141 completed surveys were returned, representing a 34.9\% response rate. The sample included seven academic faculties and various geographical sites over the whole of South Africa, including all nine provinces.

An in-depth literature review led to the compilation of a 5-point Likert scale survey instrument. The instrument collected biographical data, as well as respondents' perception on the importance of their academic work roles and their perception of their own competence in performing these roles. Respondents were requested to rate the importance and competencies from not important at all (1) to 
very important (5). Finally, the academics were allowed the opportunity to add any additional viewpoints in an open question that assisted in the final interpretations and recommendations made.

\section{Research and Ethical Procedure}

Respondents were sent an informed consent letter, accompanying the anonymous, online survey. Prior to collecting the data, permission was obtained from the ethical committee and all protocols in terms of informed consent, protection of private information, anonymity, and confidentiality were carefully observed (Unisa, 2007).

Data was imported into Microsoft Excel, checked, cleaned, and subsequently imported into the Statistical Package for the Social Sciences (SPSS). Descriptive as well as inferential statistical analysis was performed to determine the ODL academics' perception of the importance and competence related to each role, as well as to test hypotheses about significant differences between the importance and competence reported in each role. The descriptive analysis also included an importance-competence gap analysis to determine the priority training gaps that would potentially yield the biggest return on investment relatively quickly.

\section{Reliability and Validity}

Face validity was ensured by asking a number of experienced ODL academics to analyse the instrument and make recommendations for improvement. Furthermore, a pilot study with ten respondents prior to the actual data collection yielded valuable inputs for improvement. These recommendations were implemented before the instrument was distributed. Regarding the statistical analysis, Cronbach's alpha scores were calculated for each individual question to determine how the reliability of the instrument would be affected if the question was omitted. The questions included in the final instrument all had acceptable reliability scores above the 0.7 cut-off point. The Cronbach Alpha reliability score for the full instrument was 0.955 . The instrument can thus be judged highly reliable (Welman, Kruger, \& Mitchell, 2012).

\section{Statistical Analysis and Results}

The descriptive analysis included the calculation of frequencies and percentages of mean and median scores, standard deviation scores, skewness, and kurtosis. To facilitate the interpretation of the statistical results, an importance-competency gap analysis was performed based on the mean scores obtained. The mean scores obtained for each academic work role were depicted on the $x$-axle and the mean scores for academics' perception of their competence in each work role were depicted on the $y$ axle in Figure 1 below.

The findings below depict the eight training gaps with the highest perceived importance-competency gaps, thus the biggest differences between perceived importance and competencies per ODL academic work role. 


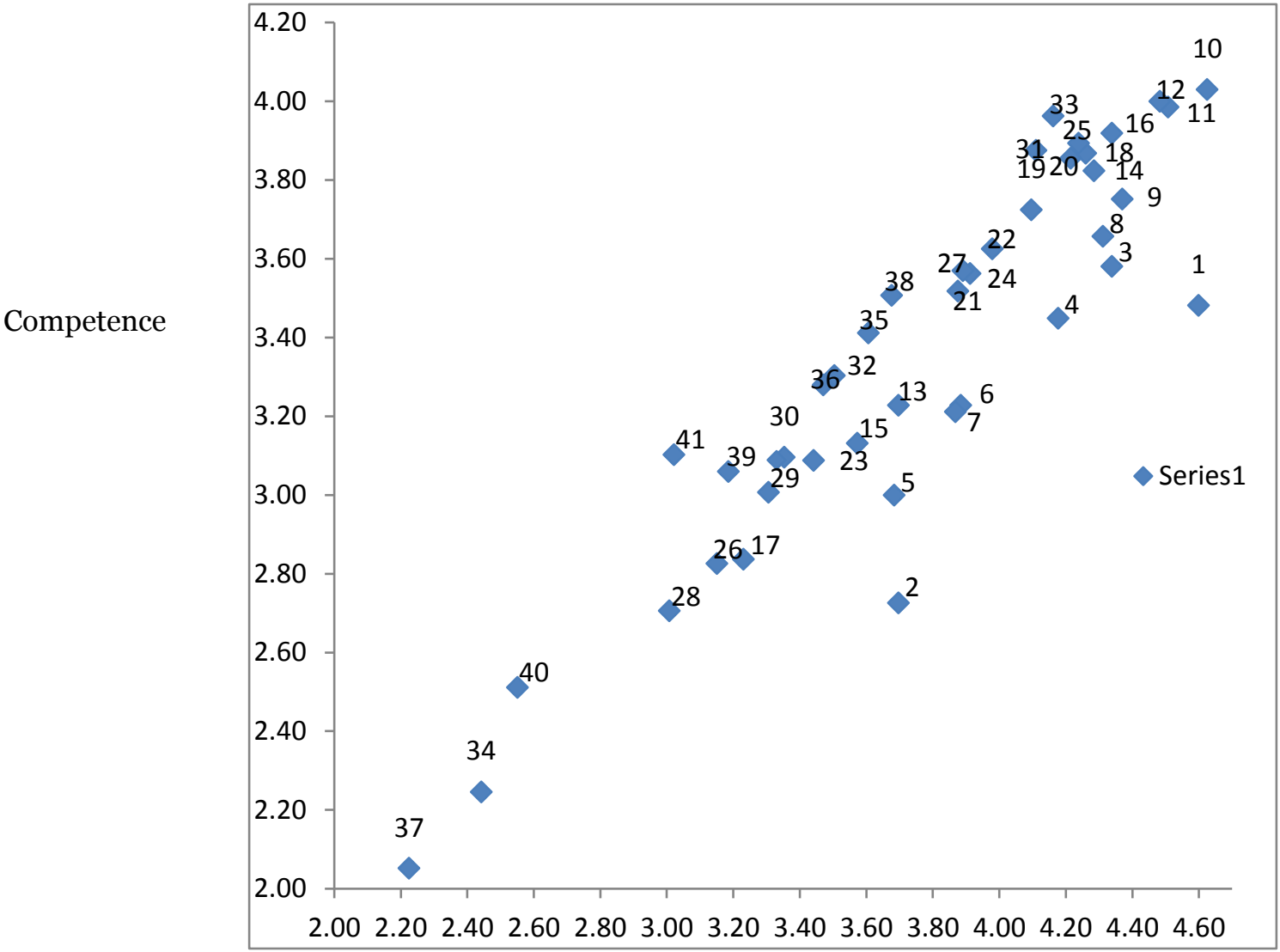

Quadrant 3: Low

potential for return

on investment
Quadrant 4: Important

competence gaps

Importance

Figure 1. Importance-Competency Analysis. This figure illustrates the most important training gaps of distance educators by comparing the importance of certain work roles with educators' current competence.

In Figure 1 above, the cut-off point used to categorise the different quarters was a value of 3 . The reason for this decision was that any mean derived from the Likert scale above 3 indicated a positive response and below 3 a negative response. An important work role would thus be expected to score a mean higher than 3, and a less important role expected to score a mean of less than 3. The same is true for the perceived competence. If the respondents' mean scores for competence in a specific role are above 3, one could accept that they feel positive about their competence in a specific academic role and view it as a strength. A mean score below 3 would then represent a lack of competence or a weakness, indicative of a training gap. Research on competency frameworks generally stops at this point. The bigger the gap, the bigger the training need, and therefore more time and effort are invested. This article, however, adopts a different approach, in that not all gaps are perceived as particularly important. Even if the training gap is relatively large, the importance of the gap is also considered before it is identified as a 
priority training gap. If ODL academics rated the work role as less important (below 3), this article argues that the university will not gain a lot by investing heavily in addressing this training gap.

Quadrant 1 in Figure 1 illustrates the high-high scenario, where academics view the role as important, but they also view their own competencies as relatively high. This quarter thus represents strengths and is labelled "On Track." Quadrant 2 represents a low-high scenario, where the role is not important, although academics view themselves as very competent in these fields. Further training would thus definitely not be recommended in this quadrant labelled "Over Investment." Quadrant 3 represents the "low return" scenario where, although academics are not competent, they also view these roles as unimportant. It would thus not make much sense to invest in unimportant work roles; even if there is an improvement it would not contribute much to efficiency and effectivity. Quadrant 4 represents the important training gaps (high-low scenario), where ODL academics feel the role is important, but their own competency is less than desirable. If the university could thus direct their resources towards illuminating these training gaps, it should make a relatively big difference in the outcomes.

Table 1

The Perceived Importance-Competence Gap of Specific Academic Work Roles (N=141)

\begin{tabular}{llll}
\hline $\begin{array}{l}\text { Quadrant 1: } \\
\text { On track }\end{array}$ & $\begin{array}{l}\text { Quadrant 2: } \\
\text { Over investments } \\
\text { (high-high) }\end{array}$ & $\begin{array}{l}\text { Quadrant 3: } \\
\text { On track (low-low) }\end{array}$ & $\begin{array}{l}\text { Quadrant 4: } \\
\text { Important competence gaps } \\
\text { (high-low) }\end{array}$ \\
\hline 1. Researcher & None & & 13. Policeperson to \\
1. Peer reviewer & & 40. Librarian & detect plagiarism \\
10. Subject specialist & 34.Technician & 6. Friendly online \\
12. Assessor & 37. Graphic & environment \\
11. Lifelong learner & designer & 7. Pedagogical expert \\
16. Writer of subject & & 5. Online expert \\
material & & 2. Frequent publisher \\
18. Course manager & & 15. Computer specialist \\
14. Facilitator & & 17. Transformation agent \\
20. Communicator & & 36. Tutor \\
25. Advisor to & & 23. Student interaction \\
students & & 29. Change agent \\
33. Teacher & 30. Strategist \\
32. Professional & & 39. Provider of emotional \\
31. Instructor of & & & \\
\hline
\end{tabular}


students

9. Designer of

subject material

19.Team member

8. Creator of new

knowledge

3. Supervisor

22. Intellectual

mentor

27. Academic

Citizenship

21. Organiser

38. Administrator

40. Librarian

24. Motivation

35. Leader of

Students support to students

41. Counsellor

26. Community

developer

28. Peacekeeper during

online student debates

17. Transformation agent

After the initial gap analysis (performed based on the differences in means), a paired samples T-test was conducted to determine if the differences calculated were statistically significant at a confidence interval of $95 \%$. The following hypotheses were formulated and tested statistically:

$\mathrm{H}_{0} \quad$ The average of the difference between the importance and the competence of academic work roles is equal to zero.

$\mathrm{H}_{\mathrm{a}} \quad$ The average of the difference between the importance and the competence of academic work roles is significantly different from zero.

The hypotheses imply that statistically, if the P-value is calculated to be less than 0.05 , the academics perceived their competence in a specific work role to be significantly less than the importance they attach to the role. The results of the statistical analyses yielded are presented in Table 2. 
Table 2

Paired Samples T-Test to Show Significance of Perceived Importance Competence Gaps

\begin{tabular}{|c|c|c|c|c|c|c|c|c|c|}
\hline & \multicolumn{3}{|c|}{ Role importance } & \multicolumn{4}{|c|}{ Current competency } & \multirow[b]{3}{*}{$\mathrm{T}$} & \multirow[b]{3}{*}{$\mathrm{p}$-value } \\
\hline & $\mathrm{N}$ & & & $\mathrm{N}$ & & & & & \\
\hline & Valid & Mean & Std & Valid & Mean & Std & Gap & & \\
\hline Researcher & 134 & 4.59 & 0.728 & 134 & 3.47 & 1.122 & 1.120 & 11.326 & 0.000 \\
\hline Publisher & 134 & 3.69 & 1.368 & 134 & 2.72 & 1.212 & 0.970 & 8.293 & 0.000 \\
\hline Supervisor & 135 & 4.33 & 1.037 & 135 & 3.58 & 1.137 & 0.749 & 8.481 & 0.000 \\
\hline Peer reviewer & 135 & 4.17 & 1.004 & 135 & 3.44 & 1.137 & 0.730 & 7.038 & 0.000 \\
\hline Online experts & 135 & 3.68 & 1.163 & 135 & 3.01 & 1.110 & 0.674 & 5.784 & 0.000 \\
\hline Friendly & 136 & 3.88 & 1.163 & 135 & 3.01 & 0.996 & 0.656 & 6.079 & 0.000 \\
\hline $\begin{array}{l}\text { Pedagogical } \\
\text { expert }\end{array}$ & 135 & 3.86 & 1.179 & 135 & 3.22 & 1.182 & 0.640 & 7.11 & 0.000 \\
\hline $\begin{array}{l}\text { Creator of new } \\
\text { knowledge }\end{array}$ & 136 & $4 \cdot 30$ & 0.855 & 136 & 3.65 & 0.346 & 0.650 & 7.601 & 0.000 \\
\hline $\begin{array}{l}\text { Designer of } \\
\text { subject material }\end{array}$ & 136 & $4 \cdot 36$ & 0.747 & 136 & 3.76 & 0.947 & 0.600 & 6.795 & 0.000 \\
\hline $\begin{array}{l}\text { Subject } \\
\text { specialist }\end{array}$ & 135 & 4.62 & 0.645 & 135 & 4.02 & 0.876 & 0.600 & 8.135 & 0.000 \\
\hline $\begin{array}{l}\text { Life-long } \\
\text { learner }\end{array}$ & 135 & 4.50 & 0.711 & 135 & 4.00 & 0.855 & 0.500 & 6.409 & 0.000 \\
\hline Assessor & 138 & 4.47 & 0.766 & 138 & 4.00 & 0.837 & 0.470 & 5.903 & 0.000 \\
\hline Police & 134 & 3.69 & 1.265 & 134 & 3.24 & 1.056 & 0.450 & 4.215 & 0.000 \\
\hline Facilitator & 135 & 4.27 & 0.850 & 135 & 3.83 & 0.815 & 0.440 & 5.138 & 0.000 \\
\hline IT specialist & 136 & $3 \cdot 55$ & 1.173 & 136 & 3.13 & 1.078 & 0.420 & 3.816 & 0.000 \\
\hline Writer & 135 & $4 \cdot 34$ & 0.830 & 135 & 3.92 & 0.939 & 0.418 & 4.889 & 0.000 \\
\hline $\begin{array}{l}\text { Transformation } \\
\text { agent }\end{array}$ & 134 & 3.22 & 1.300 & 134 & 2.83 & 1.147 & 0.390 & 4.072 & 0.000 \\
\hline Course manager & 136 & 4.27 & 0.080 & 136 & 3.87 & 0.909 & 0.402 & 4.01 & 0.000 \\
\hline Team member & 133 & 4.09 & 0.957 & 133 & 3.72 & 0.932 & 0.366 & 4.234 & 0.000 \\
\hline Communicator & 137 & 4.20 & 0.986 & 137 & 3.85 & 0.887 & 0.350 & 3.969 & 0.000 \\
\hline Organiser & 135 & 3.87 & 1.033 & 135 & 3.53 & 0.953 & 0.340 & 3.394 & 0.001 \\
\hline
\end{tabular}




\begin{tabular}{|c|c|c|c|c|c|c|c|c|c|}
\hline $\begin{array}{l}\text { Intellectual } \\
\text { mentor }\end{array}$ & 135 & 3.96 & 1.068 & 135 & 3.61 & 1.044 & 0.351 & 3.921 & 0.000 \\
\hline $\begin{array}{l}\text { Interaction } \\
\text { facilitator }\end{array}$ & 135 & 3.44 & 1.182 & 135 & 3.07 & 1.048 & 0.371 & 4.23 & 0.000 \\
\hline Motivator & 135 & 3.91 & 1.089 & 135 & 3.58 & 0.988 & 0.332 & $3 \cdot 323$ & 0.001 \\
\hline $\begin{array}{l}\text { Advisor to } \\
\text { students }\end{array}$ & 140 & 4.25 & 0.874 & 140 & 3.89 & 0.887 & 0.356 & 3.889 & 0.000 \\
\hline $\begin{array}{l}\text { Community } \\
\text { developer }\end{array}$ & 138 & 3.13 & 1.283 & 138 & 2.83 & 1.094 & 0.304 & 3.075 & 0.003 \\
\hline $\begin{array}{l}\text { Academic } \\
\text { citizenship }\end{array}$ & 143 & 3.87 & 1.067 & 143 & 3.57 & 1.032 & 0.301 & $3 \cdot 301$ & 0.010 \\
\hline Peacekeeper & 135 & 2.99 & 1.296 & 135 & 2.70 & 1.053 & 0.290 & 2.65 & 0.009 \\
\hline Change agent & 138 & 3.28 & 1.260 & 138 & 3.00 & 1.114 & 0.280 & 2.616 & 0.010 \\
\hline Strategist & 135 & $3 \cdot 34$ & 1.345 & 135 & 3.08 & 1.113 & 0.260 & 2.6 & 0.010 \\
\hline Instructor & 135 & 4.13 & 0.934 & 135 & 3.87 & 0.879 & 0.260 & 2.848 & 0.005 \\
\hline Professional & 134 & 3.49 & 1.535 & 134 & $3 \cdot 30$ & 1.280 & 0.186 & 2.213 & 0.029 \\
\hline Teacher & 134 & 4.16 & 0.995 & 134 & 3.96 & 0.883 & 0.199 & 2.42 & 0.017 \\
\hline Technician & 134 & 2.44 & 1.186 & 134 & 2.25 & 1.036 & 0.195 & 2.066 & 0.041 \\
\hline Leader & 135 & 3.59 & 1.242 & 135 & 3.40 & 1.059 & 0.190 & 1.908 & 0.059 \\
\hline Tutor & 135 & 3.47 & 1.25 & 135 & 3.27 & 1.147 & 0.201 & 2.126 & 0.035 \\
\hline $\begin{array}{l}\text { Graphic } \\
\text { designer }\end{array}$ & 135 & 2.24 & 1.170 & 135 & 2.05 & 1.010 & 0.188 & 1.725 & 0.087 \\
\hline Administrator & 142 & 3.65 & 1.197 & 142 & 3.51 & 0.967 & 0.143 & 1.246 & 0.215 \\
\hline $\begin{array}{l}\text { Emotional } \\
\text { supporter }\end{array}$ & 134 & 3.17 & 1.186 & 134 & 3.05 & 1.028 & 0.120 & 1.268 & 0.207 \\
\hline Librarian & 135 & 2.56 & 1.336 & 135 & 2.51 & 1.184 & 0.050 & 0.403 & 0.687 \\
\hline Counsellor & 137 & 2.98 & 1.257 & 137 & 3.10 & 1.120 & -0.122 & -1.069 & 0.287 \\
\hline
\end{tabular}

Previous studies often only determined the training gaps by comparing the means or, at most, standardised the scores by calculating the T-scores (Chang, Shen, \& Liu, 2014). This study, however, used the T-scores to determine the size of the standardised competence gaps and also analysed the importance of these gaps (as was illustrated in Figure 1). Of specific importance is thus the significant competence gaps (Quadrant 4), which are also deemed important to address after standardisation. 
From Table 2, it is clear that the priority importance-competence gaps are perceived as being a frequent publisher of new research, becoming an online teaching expert, creating a friendly online environment, being a pedagogical expert, computer expert, transformation agent, student interaction facilitator, community developer, peacekeeper during online debates, change agent, strategist, tutor, emotional supporter, and counsellor.

The empirical findings confirmed that there are urgent training gaps in terms of important issues including: writing, designing, and facilitating subject material; and being a teacher, subject specialist, mentor, and supervisor to students. However, it was also confirmed that the roles in Quadrant 1 are on track. It is thus argued that in this constricted environment, academics are skilled enough to manage on the short to medium-term in these roles.

Although the academics did not perceive the roles in Quadrant 1 as a priority, it is advised that these skills should be continuously updated. It may be that they are of the opinion that these are not pressing needs as they are skilled and experienced enough to cope, and that there are other more pressing needs where a bigger difference could be made.

\section{Discussion}

In addressing the call for more research in universities in the developing world (Kuanda, 2012) and the recognition of the challenge of an "expanded scope of their job" (p. 1519) and "management requirements," (Seale \& Cross, 2016, p. 1519) this research aims to provide some guidance on how to allocate scarce resources to "get more for less" (Seale \& Cross, 2016, p. 1524). Restricted resources imply that developing world universities need to plan strategically and use their available resources where it is likely to have the biggest organisational impact. Organisations, including universities, should commit their resources to those training activities that can best help in achieving its objectives (Rothmann \& Cooper, 2015). The importance-competence analysis used in this paper aims to guide decision-makers towards having the most significant impact and fostering positive change over the shortest possible time period. From my point of view a performance-competency analysis may be beneficial in deciding how to distribute available resources to achieve the most efficient outcomes possible. I believe that as the job of the DE continuously becomes more complex and varied, generic training programmes increasingly become irrelevant and the demand for targeted strategic HRD efforts progressively increases.

Current academic requirements in Higher Education institutions worldwide include excellent teaching practices and enabling course structures that enhance the learning experience and encourage interaction (Okendu, 2012). Thus, increased competency of academics is associated with more successful learning (Okendu, 2012), and successful learning ultimately leads to successful students and effective organisations. The success of universities as organisations is thus dependent on the competency and skill of academic staff members.

The question is thus not if training gaps should be addressed, but how the process should be managed to bridge the competency gaps of distance learning academics' in the most efficient way possible. For this reason, it was decided that that the importance-performance theory of Lovelock et al. (1998) would offer an appropriate lens to study where scarce resources should be allocated at Unisa to have the 
biggest positive impact. We believe that the importance-performance theory will also enable university policy makers to decide which learning interventions to prioritise for their academic staff and which to leave to the medium term, as well as to identify those work roles where even significant time and effort spent on training will likely lead to little improvement in organisational effectiveness. In an environment of dwindling resources (inputs), it may be advisable to address these challenges at a later stage.

In most universities, including Unisa, the three pillars of the academic job include: (a) research, (b) teaching and learning, and (c) academic citizenship (Unisa, 2016). In our study, the first six priority competence gaps, indicated in Table 2, mainly allude to the first two aforementioned pillars. These significant competency gaps necessitate the exploration of the possible implications for distance universities as entities, as well as individual academics per se. The discussion of the research results will be structured following these two pillars as sub-headings.

\section{Research Competencies}

The first training priority reported by educators, referring to becoming a frequent publisher of new knowledge, may be indicative of the managerial pressure that academics experience to publish new research results consistently. When interpreted from a systems theory perspective, this implies that quality outputs must be produced at a rapid rate, without necessarily increasing inputs in the form of increased resources, a scenario described by Seale and Cross (2016) as "doing more with less" (p. 1523). The empirical results thus show that academics experience a need to improve their knowledge, skills, and attitudes about these scholarly activities to enable them to produce more outputs faster. The pressure to publish has to be interpreted against the milieu of intense competition between universities, as well as within the same university, which gave rise to the whole idea of "academic productivity" (Jamieson, 2004, p. 22). Unfortunately, evidence suggests that the demand for increased quantity often overrides scholarly concerns for quality of publications (Jamieson, 2004).

I believe the idea that teaching and research are necessarily two separate activities is obsolete. Schouteden, Verburgh and Elen (2016) stress the importance of informing teaching through research activities. Davis, Jansen van Rensburg, and Venter (2016) note the drive towards holding faculty accountable for both the quality of research, and the quality of teaching and learning via the use of integrated objectives and performance management. However, a general paucity of insight on how to integrate research findings into teaching hampers the process (Davis et al., 2016). In my opinion faculty should thus be supported in learning new skills to conduct appropriate research effectively and use the findings to inform their teaching and learning practices.

\section{Teaching and Learning Competencies}

The empirical results indicated that distance faculty experienced an important and immediate need to learn how to become online experts using TEL, create a friendly online environment, and become pedagogical experts. The results of this study thus prove distance learning faculty in a developing world context need to learn how to facilitate learning by creating a sense of online community. It seems that respondents perceived that to become successful digital academics, they need to learn how to be digital conversation stimulators, coaches, and mentors. This may be related to what Siemens (2008, p.10) coined "connections" between specialised information sets. Digital academics thus need the ability to guide learners to form connections between complex information sets as more complex information is 
continually acquired. This ability should support students in learning how to navigate an increasingly complex and changing world.

It is noteworthy that for learning to be effective, these skills should be taught in an integrative manner, in which distance learning academics are taught to apply pedagogical principles effectively with the support of computer technology.

\section{Conclusion}

In conclusion, this article contributes to the body of knowledge by showing that simply offering a list of training programmes in itself is not good enough to bridge the competency gaps of distance learning academics' in developing world contexts. The article illustrated that the complex university contexts in developing countries demand an approach where outputs are maximised within the constraints of economic reality. Strategically, for distance learning universities to remain competitive, it is imperative that they engage in targeted, custom-made training and development interventions based on importance-competence analyses. Therefore a holistic approach where both the size of the training gap, as well as the importance and urgency of addressing the training gap is acknowledged, is proposed as one method of expanding existing resources to achieve better results in equipping distance faculty with desperately needed knowledge, skills, and attitudes. In future, faculty development programs should thus consider both the size of the gap, and the importance of the gap to the individual faculty member and the university. These programmes should aim to maximise return on investment by focussing on interventions in which the biggest difference can be made, with the limited resources available. The results of this study emphasize the importance of timeously directing available resources towards interventions that will empower faculty to integrate sound pedagogical principles with new technology. This is a break from traditional approaches, within which the biggest training gaps receive priority attention, and the educators' perceived importance of the skill or knowledge gap (which impacts their ability to perform their jobs) is not considered.

Future research, investigating if the identified competencies are also regarded as important and urgent in other universities, and specifically in other distance learning universities, globally, would be insightful. The main limitation of this study was that the research was conducted in only one mega distance learning university and should therefore be replicated in other universities, before the findings may be generalised.

As Higher Education faces numerous challenges and practical constraints, it is hoped that this article will provide a new perspective on how to address some of these challenges in a responsible and strategically responsive manner. The new knowledge presented in this article presents a novel way of managing scarce university resources, to the benefit of the whole Higher Education community, namely distance learning academics, learners, and universities alike. 


\section{References}

Altbach, P.G. (2014). The emergence of a field: Research and training in higher education. Studies in Higher Education, 39(8), 1320-1320. doi:10.1080/03075079.2014.949541

Arinto, P.B. (2013). A framework for developing competencies in open and distance learning. International Review of Research in Open and Distance Learning, 4(1), 167185. doi.org/10.19173/irrodl.v14i1.1393

Axley, L. (2008). Competency: A concept analysis. Nursing Forum, 43(4), 214-222. doi: 10.1111/j.1744-6198.2008.00115

Baran, E., Correia, A., \& Thompson, A. (2011). Transforming online teaching practice: Critical analysis of the literature on the roles and competencies of online teachers. Distance Education, 32(3), 421-439. https://doi.org/10.1080/01587919.2011.610293

Bawane, J., \& Spector, J.M. (2009). Prioritisation of online instructor roles: Implications for competency based teacher education programmes. Distance Education, 3o(3), 383. DOI: 10.1080/01587910903236536

Berge, Z.L. (2008). Changing instructor's roles in virtual worlds. The Quarterly Review of Distance Education, 9(4), 407-414. Retrieved from https://www.learntechlib.org/p/106706/

Bezuidenhout, A. (2013, September-October). The evolving work context of the ODL academic. Paper presented at the UNISA International Cambridge Open, Distance and eLearning Conference, Cape Town.

Bezuidenhout, A. (2015). Implications of distance educator's changing work role for academic workload. Distance Education. Retrieved from http://www.tandfonline.com/action/showCitFormats?doi=10.1080/01587919.2015.1055055

Bezuidenhout, A. \& Cilliers, F.V.N. (2010). Burnout, work engagement, and sense of coherence in female academics at two tertiary institutions. South African Journal of Industrial Psychology, 36(1), 1-10. Doi.10.4102/ sajip.v36i1.872

Biddle, B.J. (1986). Recent developments in role theory. Annual Review of Sociology, 12, 67-92. doi.org/10.1146/annurev.so.12.080186.000435

Chang, C., Shen, H-Y., \& Liu, Z-F. (2014). University faculty's perspectives on the roles of einstructors and their online instruction practice. The International Review of Research in Open and Distributed Learning, 15(3). doi:http://dx.doi.org/10.19173/irrodl.v15i3.1654

Common Wealth of Learning and Asian Development Bank. (1999). Learner support in open and distance learning: Training toolkit. Retrieved from https://www.col.org/resources/learnersupport-open-and-distance-learning-training-toolkit

Davis, A., Jansen van Rensburg, M., \& Venter, P. (2016). The impact of managerialism on the strategy work of university middle managers. Studies in Higher Education 41(8), 1480-1494. doi: 10.1080/03075079.2014.981518 
De Coi, J.L., Herder, E., Koesling, A. Lofi, C., Olmedilla, D., Papapetrou, O., \& Siberski, W. (2007). A model for competence gap analysis. European Institute for E-learning. Retrieved from http://www.olmedilla.info/pub/2007/2007_WEBIST_competence.pdf

Dimri, A.K., \& Misra, A.K. (2006). Training programmes for distance education professionals: An analytical assessment. Turkish Online Journal of Distance Education-TOJDE 7(4). Retrieved from

http://file:///C:/Users/bezuia/Downloads/Training_Programmes_for_Distance_Education _Profess.pdf

Gregory, M. S-J., \& Lodge, J.M. (2015). Academic workload: The silent barrier to the implementation of technology-enhanced learning strategies in higher education. Distance Education. doi: /10.1080/01587919.2015.1055056

Hamel, G., \& Prahad, C.K. (1989). Strategic intent. Harvard Business Review, 67(3), 63-78. Retrieved from https://hbr.org/2005/07/strategic-intent

Jamieson, P. (2004). The University as workplace. Preparing lecturers to work in online environments. The Quarterly Review of Distance Education, 5(1), 21-27. Retrieved from https://www.learntechlib.org/p/106779/

Kuanda, L. (2012). Curriculum internationalisation in an African context. University World News, 242. Retrieved from http://www.universityworldnews.com/article.php?story=20121003103951872

Leibowitz, B., Bozalek, V., Van Schalkwyk, S., \& Winberg, C. (2015). Institutional context matters: The professional development of academics as teachers in South Africa. Higher Education, 69, 315-330. doi: 10.1007/s10734-014-9777-2

Lorenzetti, J. (2009). Developing faculty competency in online pedagogy. Distance Education Report, 13(18), 5-8. Retrieved from http://search.ebscohost.com/login.aspx?direct $=$ true\&db=a9h\&AN=44476927 \&site $=$ ehost$\underline{\text { live }}$

Lovelock, C., Patterson, P.G., \& Walker, R.H. (1998). Service marketing. Sydney: Prentice-Hall.

Markus, L., Cooper-Thomas, H., \& Allpress, K. (2005). Confounded by competencies? An evaluation of the evolution and use of competency models. New Zealand Journal of Psychology, 34(2), 117-127. Retrieved from http://citeseerx.ist.psu.edu/viewdoc/download?doi=10.1.1.468.9642\&rep=rep1\&type=pdf

Martilla, J.A., \& James, J.C. (1977). Performance Analysis. Journal of Marketing, 41(1), 77-79. DOI: $10.2307 / 1250495$

McClelland, D. C., \& Boyatzis, R.E. (1980). Opportunities for counsellors from the competency assessment movement. Personnel and Guidance Journal, 368-372. doi.org/10.1002/j.21644918.1980.tboo415.x 
Moore, M.G. (2007). The theory of transactional distance. In Handbook of distance education (2nd ed.; pp. 89-108). Mahwah, NJ: Lawrence Erlbaum Associates.

Munoz Carril, P.C., Gonzalez Sanmamed, M., \& Hernández Sellés, N. (2013). Pedagogical roles and competencies of university teachers practicing in the e-learning environment. The International Review of Research in Open and Distributed Learning, 14(3), p. 462-487. Retrieved from doi:http://dx.doi.org/10.19173/irrodl.v14i3.1477

Naidu, S. (2010, May). Unpacking the affordances of technology for e-learning. In ODL Occasional Lecture Series. Unisa, Pretoria.

Norton, M.S. (2008). Human resources administration for educational leaders. Sage. http://dx.doi.org/10.4135/9781452274997.n7

Okendu, J.N. (2012). Strategic planning of university human resource programs and academic staff performance. Developing Country Studies, 2(5), 30-35.

Panda, S., \& Mishra, S. (2007). E-Learning in a mega open university: Faculty attitude, barriers, and motivators. Educational Media International, 14(1), 324-338. doi.org/10.108o/09523980701680854

Poalses, J., Joubert, J.P.R., Bezuidenhout, A., \& Nienaber, H. (2014). College of economic and management sciences occupational stress and risk assessment. Pretoria: University of South Africa.

Rothmann, I., \& Cooper, C.L. (2015). Work and organizational psychology. London: Routledge.

Saunders, M. L., Lewis, P., \& Thornhill, A. (2009). Research methods for business students (5th ed.). Harlow, England: Prentice Hall.

Schouteden, W., Verburgh, A., \& Elen, J. (2016). Teachers' general and contextualised research conceptions. Studies in Higher Education, 41(1), 79-94. doi:10.1080/03075079.2014.914915.

Seale, O., \& Cross, M. (2016). Leading and managing in complexity: the case of South African deans. Studies in Higher Education, 41(8), 1514-1532. doi:10.1080/03075079.2014.988705.

Siemens, G. (2008). Learning and knowing in networks: Changing roles for educators and designers. Retrieved from http://www.ingedewaard.net/papers/connectivism L2008/siemens Learning Knowing inNetworks changingRolesForEducatorsAndDesigners . $\mathrm{pdf}$

Sparrow, P. (1995). Organisational competencies: A valid approach for the future? International Journal of Selection and Assessment, 3(3), 168-177. doi.org/10.1111/j.14682389.1995.tbooo24.x

Unisa. (2007). Unisa policy on research ethics. Retrieved from http://www.unisa.ac.za/contents/research/docs/ResearchEthicsPolicy apprvCounc 21Sept 07.pdf 
Unisa. (2016). Research and innovation report @ Unisa. Retrieved from

http://www.unisa.ac.za/static/corporate_web/Content/Research\%20\&\%20innovation/Resea rch\%20reports/2016/unisa-research-report2016.pdf

Varvel, V. (2007). Master online teacher competences. Online Journal of Distance Learning Administration 1O(1). Retrieved from http://www.westga.edu/ distance/ojdla/spring101/varvel101.htm

Welman, C., Kruger, F., \& Mitchell, B. (2010). Research methodology (3rd ed.). Cape Town: Oxford.

Athabasca

University

(c) (7) 